\title{
Saberes e fazeres dos professores na educação profissional de jovens e adultos
}

\author{
Telma Alves \& Maria Cecilia Fantinato
}

\begin{abstract}
Resumo:
Este trabalho trata de uma investigação que teve como objetivo analisar desafios teórico-práticos do trabalho docente no curso de Manutenção e Suporte em Informática, que atende ao Programa da Educação Básica Integrada à Educação Profissional Técnica de Nível Médio, na modalidade Educação de Jovens e Adultos (EJA), uma política do governo Lula da Silva implementada na Rede Federal, em 2006. Os sujeitos da investigação foram os professores das disciplinas Física, Química e Matemática, que compõem a formação geral, e das disciplinas de Informática, que compõem a formação profissional. A pesquisa foi realizada com abordagem qualitativa, na forma de estudo de caso, e teve nas entrevistas com os professores, inspiradas no método compreensivo, a principal fonte do material empírico coletado. Através da análise de conteúdo e considerando o trabalho docente como um trabalho imaterial que se realiza pelas/nas interações humanas, buscamos, pela palavra dos professores, desafios e especificidades que se impõem na educação profissional e na modalidade EJA. Os resultados apontaram que a formação inicial dos professores para a EJA ainda é incipiente e que o conviver (pelo falar e ouvir) com linguagens e saberes diversos é um desafio.
\end{abstract}

Palavras-chave:

educação profissional; ensino médio; educação de jovens e adultos. 


\title{
Knowledge and practices of teachers in the vocational education, in the of youth and adult education
}

\begin{abstract}
This article aims to analyze the theoretical-practical challenges posed to the teaching in the Informatics Maintenance and Support course that integrates the Basic Education component of the Technical Professional Education of Medium Level Program, in the modality of Youth and Adults Education (YAE). It is a government policy from Lula da Silva president, implemented in 2006. The subjects of the investigation were the teachers of the Physics, Chemistry and Mathematics courses that compose the general formation and of the Information Technology course that compose the professional formation. The research was carried out with a qualitative approach, in the form of a case study, and the interviews with the teachers, inspired by the comprehensive method, were the main source of the collected empirical material. Through the content analysis and considering that teaching is an immaterial work that is performed by / in human interactions, we seek, through teachers' words, challenges and specificities that are imposed in professional education programs and in the YAE modality. The results pointed out that the initial teachers education for the YAE is still incipient and that living together (speaking and listening) with different languages and knowledge is a challenge.
\end{abstract}

Keywords: professional education; high school; youth and adult education.

\section{Conocimientos y prácticas de los profesores de formación profesional en la Educación de jóvenes y adultos}

Resumen: Este trabajo trata de una investigación que tuvo como objetivo analizar desafíos teórico-prácticos del trabajo docente en el curso de Mantenimiento y Soporte en Informática que atiende al Programa de Educación Básica Integrada a la Educación Profesional Técnica de Nivel Medio, en la modalidad Educación de Jóvenes y Adultos (EJA), política del gobierno de Lula da Silva implementada en la Red Federal en 2006. Los sujetos de la investigación fueron los profesores de las disciplinas Física, Química, Matemáticas que componen la formación general y de las disciplinas de Informática que componen la formación profesional. La investigación fue realizada con abordaje cualitativo, como estudio de caso, y tuvo en las entrevistas con los profesores, inspiradas en el método comprensivo, la principal fuente del material empírico recogido. A través del análisis de contenido y considerando el trabajo docente como un trabajo inmaterial que se realiza por/en las interacciones humanas, buscamos, por la palabra de los profesores, desafíos y especificidades que se imponen en la educación profesional y en la modalidad EJA. Los resultados apuntaron que la formación inicial de los profesores para la EJA todavía es incipiente y que el convivir (por el hablar y oír) con lenguajes y saberes diversos es un desafío.

Palabras clave: educación profesional; escuela secundaria; educación de jóvenes y adultos.

\section{Connaissances et pratiques des enseignants de l'enseignement professionnel, dans l'éducation des jeunes et des adultes}

Résumé: Cet article présente une recherche dont l'objectif était d'analyser les défis théoriques et pratiques du travail enseignant dans le cours de Maintenance et Support Informatique, inscrit dans le cadre du Programme d'Éducation de Base Intégrée à l'Éducation Professionnelle Technique au Lycée, en modalité Éducation des Jeunes et des Adultes (EJA), une politique du gouvernement Lula da Silva mise en pratique dans le Réseau Fédéral en 2006. Les sujets de l'enquête étaient les professeurs des disciplines Physique, Chimie et Mathématiques, qui composent la formation générale, et des disciplines de l'Informatique, qui composent la formation professionnelle. Cette recherche a été menée en approche qualitative, sous forme d'étude de cas. Les entretiens avec les professeurs, inspirés de la méthode compréhensive, ont été la source principale du matériel rassemblé. A travers l'analyse de contenu, et considérant le travail enseignant comme un travail immatériel fait par / dans les interactions humaines, nous avons cherché, dans la parole des enseignants, les défis et les spécificités qui s'imposent dans l'enseignement professionnel et dans la modalité EJA. Les résultats ont indiqué que la formation initiale des enseignants en EJA est encore peu développé et que la convivialité (parler et entendre) avec de différents langages et savoirs est encore un défi.

Mots-clés: éducation pofessionnelle; lycée; enseignement des jeunes et des adultes. 


\section{Introdução}

Este trabalho trata de uma investigação, concluída em julho de 2018, que teve como objetivo geral analisar criticamente o trabalho docente em um curso técnico de nível médio integrado ao ensino médio na modalidade de jovens e adultos, no sentido de poder contribuir para as discussões sobre a formação inicial e continuada dos professores da Educação Básica. O curso técnico é o de Manutenção e Suporte em Informática, que atende o Programa de Educação Profissional Integrada à Educação Básica, na modalidade de Educação de Jovens e Adultos, doravante PROEJA/MSI.

O PROEJA é um programa do governo Lula da Silva instituído pelo Decreto $n^{\circ}$ 5840/06, de 13 de julho de 2006, que aproxima as modalidades Educação de Jovens e Adultos (EJA) e Educação Profissional (EP). Tal programa foi implantado no campus Rio de Janeiro do Instituto Federal de Educação, Ciência e Tecnologia do Rio de Janeiro (IFRJ), em setembro de 2006.

O PROEJA impõe o desafio de integrar três campos da educação brasileira que, historicamente, têm trajetórias distintas e distantes: o ensino médio, a formação profissional e a EJA (Moura \& Henrique, 2012). A formação profissional foi tratada como "treinamento eficiente da mão de obra necessária ao atendimento do projeto capitalista" (Machado, 2009, p. 27), enquanto a EJA foi, por muito tempo, foco de ações no sentido de compensar a falta de acesso à leitura e à escrita como bens sociais. $O$ ensino médio continua marcado, desde a década de 1940, pela dualidade, de caráter estrutural, do ensino secundário entre técnico e propedêutico. Segundo Santos (2015), tal dualidade tem origem no fato de que:

o ensino profissional, desde o período imperial, havia sido inteiramente marginalizado em relação à educação secundária, tendo em vista que o primeiro estava destinado a formar indivíduos para o trabalho manual, enquanto o segundo se destinava às elites, isto é, aos que ocupariam as funções de dirigentes (Santos, 2015, p. 218).

A Rede Federal de Educação Profissional, que passou por transformações ao longo do tempo, é considerada desde os anos 60/70 como de excelência na oferta de ensino médio e cursos técnicos de nível médio. Houve períodos em que os cursos técnicos foram ofertados na forma integrada; em outros, essa oferta ocorreu de forma separada. A experiência da Rede Federal, associada à qualidade dos cursos que oferece, faz dela um local de possibilidades para a implantação do PROEJA. Em contrapartida, sua (quase) nenhuma experiência com a modalidade EJA caracteriza uma limitação para os objetivos do PROEJA. 
O curso PROEJA/MSI tem previsão de encontros semanais, porém esses encontros, ao longo do tempo, vêm perdendo a periodicidade, por vários motivos. Dentre eles, podemos citar o fato de que alguns professores, por ministrarem aulas em outros cursos, no mesmo horário, não podem participar das discussões pedagógicas. Interrogamo-nos sobre as consequências dessa impossibilidade para o trabalho docente.

A complexidade do curso PROEJA/MSI, caracterizada por elementos como a pedagogia de projetos e a educação profissional integrada ao ensino médio na modalidade EJA, tem repercussão no trabalho docente de professores de todas as disciplinas que compõem a matriz curricular do curso. Optamos, então, por realizar a investigação com os professores das disciplinas Física, Química e Matemática, e das disciplinas que se relacionam à formação profissional - a Informática.

Em torno do trabalho docente realizado pelos professores dessas disciplinas, algumas questões motivaram a investigação:

- Que formação inicial/acadêmica eles trazem para o desenvolvimento do seu trabalho na EJA?

- Quais dificuldades os professores encontram na tarefa de ensinar sua disciplina no PROEJA/MSI?

- De que maneira sua formação, suas socializações e suas experiências contribuem para a realização do trabalho docente?

Decidimos responder à seguinte pergunta: que saberes e fazeres os professores desenvolveram no seu trabalho docente de ensinar a jovens e adultos na educação profissional de nível médio? A pergunta foi respondida pelo estudo de desafios e especificidades do trabalho docente no curso PROEJA/MSI do campus Rio de Janeiro.

No desenvolvimento deste texto, relatamos as principais concepções teóricas que fundam nossa compreensão do trabalho docente e a metodologia eleita para atingir os objetivos. Em seguida, registramos fragmentos significativos das entrevistas e suas análises. As reflexões que compartilhamos aqui são uma parte da densa descrição feita ao final da investigação, após a análise de conteúdo, com o objetivo de compreender os relatos dos professores.

Em confronto com outras fontes, tais relatos nos permitiram sustentar a importância do diálogo entre linguagens e saberes de diversas áreas para a produção de conhecimentos que contribuam para as formações docentes inicial e continuada.

\section{Referencial teórico}

Saviani (2013) nos explica que o homem produz sua existência pela transformação da natureza, ou seja, pelo trabalho. Assim, "o trabalho instaura-se a partir do momento em que seu agente antecipa mentalmente a finalidade da ação" (Saviani, 2013, p. 11). 
No caso do trabalho docente, essa antecipação se dá quando o professor representa mentalmente os aspectos do conhecimento da Ciência, da Ética e da Arte para produzir "ideias, conceitos, valores, símbolos, hábitos, atitudes, habilidades" (Saviani, 2013, p. 12). Decorre, então, que a natureza do trabalho docente é a de um trabalho não material. Além disso, o ato de ensinar não se separa da produção desse ato e nem de seu consumo.

Se o trabalho docente, como trabalho imaterial, produz ideias, conceitos, valores, símbolos, hábitos, atitudes e habilidades, tais elementos não interessam como exteriores ao homem, mas sim pela necessidade de que os estudantes os assimilem como uma segunda natureza, adquirida através do trabalho humano sobre o humano. Daí a especificidade do trabalho docente como "o ato de produzir, direta e intencionalmente, em cada indivíduo singular, a humanidade que é produzida histórica e coletivamente pelo conjunto dos homens" (Saviani, 2013, p. 13).

A investigação que apresentamos neste trabalho se insere num movimento iniciado nas décadas de 80-90, no qual as pesquisas sobre ensino se preocupavam com a constituição de um repertório de conhecimentos profissionais para o ensino, pois o professor era visto como um profissional que deve possuir saberes que, assim como médicos, engenheiros ou advogados, permitam organizar seu trabalho.

Entendemos que esse movimento de preocupação com a profissão ou ofício do professor se relaciona com as transformações apontadas por Oliveira (2004), Lessard e Tardif (2008), Nicodemos (2013), Tardif e Lessard (2014), dentre outros, nomeadamente relacionadas às reformas educacionais no Brasil e no mundo a partir de 1960, que contribuem para a (des)profissionalização docente.

O trabalho docente foi abordado pelo exame das relações entre as condições subjetivas e as condições objetivas (Basso, 1998). Dentre as primeiras, identificamos a formação pré-profissional, a experiência, a formação profissional inicial, dentre outras possíveis. Dentre as segundas, destacamos a estrutura do IFRJ, a pedagogia de projetos sobre a qual o curso foi embasado, as condições materiais (laboratórios, material didático, estrutura da matriz curricular, participação no planejamento, etc.), incluindo plano da carreira docente.

No contexto da educação formal, que qualitativamente é diferente, já que sua finalidade é "a apropriação de instrumentos culturais básicos que permitam a elaboração de entendimento da realidade social e promoção do desenvolvimento individual" (Basso, 1998, p. 22), ocorrem interações intrínsecas ao convívio escolar, eivadas pela formação familiar. No caso de jovens e adultos acima de 18 anos, destinatários do PROEJA, podem-se acrescentar as experiências da prática concreta do mundo do trabalho e da luta pela sobrevivência.

Além de compreender o trabalho docente pela sua natureza e sua especificidade, recorremos a duas categorias - significado e sentido - por entendermos que uma vez 
identificadas na análise de conteúdo das entrevistas, seria possível compreender meIhor como o trabalho dos professores é desenvolvido no curso PROEJA/MSI.

O significado do trabalho dos professores é formado pela associação das operações que estes fazem conscientemente para produzir o conjunto de valores, conceitos e habilidades, à finalidade de que sejam assimilados pelos jovens e adultos (Basso, 1998). Para essa associação das operações à finalidade é importante considerar a subjetividade dos professores. Tardif (2001) afirma que a subjetividade faz parte do postulado central pelo qual professores possuem saberes específicos que, na realização do seu trabalho, são utilizados e desenvolvidos por eles. É possível, então, afirmar que o significado do trabalho docente está intimamente ligado às condições subjetivas tais como formação inicial e experiência.

O sentido se dá pela consciência de sua participação na produção do significado do que faz (Basso, 1998). O sentido se expressa pela motivação do professor em identificar suas opções, suas decisões e seus saberes na execução de suas tarefas em sala de aula e na escola.

Mas essa identificação de si mesmo no trabalho produzido não depende somente das condições subjetivas, mas também está relacionada às condições dadas pela estrutura escolar para que o professor coloque suas ações em prática, ou seja, depende das condições objetivas a que estão sujeitos os professores. Dessa forma, percebe-se a articulação entre significado e sentido, a qual nos permite elaborar a seguinte pergunta: o professor que produz o trabalho imaterial de ensinar pode se reconhecer no produto desse trabalho? Caso a resposta a essa pergunta seja negativa, pode-se dizer que houve a separação entre o sentido e o significado dessa atividade. Essa separação torna o trabalho docente alienado do professor.

Esses referenciais teóricos nos embasaram para realizar a compreensão do trabaIho docente, nosso objeto de estudo nesta investigação.

\section{Metodologia}

Por termos consciência do quanto é complexa a tarefa de ensinar e pelo interesse de compreender, através das perspectivas dos próprios professores, o trabalho docente no PROEJA/MSI e os significados atribuídos a ele, escolhemos a investigação qualitativa como forma de abordar o objeto, uma vez que os dados que buscamos coletar são, segundo Bogdan e Biklen (1994), "ricos em pormenores descritivos relativos a pessoas, locais e conversas" (p. 16).

Assim, no sentido de realizar o estudo qualitativo do trabalho docente, adotamos as seguintes atitudes:

- Coleta de dados no ambiente natural de atuação dos professores, o campus Rio de Janeiro, sendo a pesquisadora o instrumento principal da investigação; 
- O uso da forma descritiva para apresentar a riqueza de dados do contexto, da história da instituição e da implantação do curso;

- Preocupação maior com o processo de mobilização/construção de saberes e fazeres e sua relação com desafios teórico-práticos do trabalho docente no PROEJA/MSI;

- Raciocínio de análise não dedutivo. Apesar de ter como hipótese que os professores buscam superar as possíveis dificuldades das especificidades que caracterizam o PROEJA/MSI através de saberes e fazeres diretamente relacionados ao seu percurso da formação acadêmica ou às suas experiências de vida, não temos a preocupação de buscar evidências que a comprovem, pois as elaborações teóricas vão se consolidar a partir dos dados inspecionados;

- Investigação que visa expor o dinamismo interno - que ainda parece imperceptível ao observador externo - pela perspectiva dos professores, revelando o significado que eles mesmos conferem aos desafios, saberes e fazeres do trabalho docente que realizam.

Em acordo com a ideia de que "num estudo analítico, as decisões são tomadas à medida que este avança" (Bogdan \& Biklen, 1994, p. 85), fomos percebendo a necessidade de apreender mais dados sobre o curso técnico - como foi sua concepção teórica, sua implantação, parte de seu percurso - no qual os sujeitos da investigação ensinavam/ensinam. Outra decisão tomada durante o processo de investigação foi assumir uma postura de observação sobre o tratamento - opiniões, atitudes, decisões - dado ao PROEJA/MSI dentro do campus Rio de Janeiro pelos atores - professores e gestores - da instituição.

Assim, a investigação se configura como um estudo de caso, no qual o trabalho docente desse grupo de professores dentro desse curso técnico, especificamente, é tratado como um todo, "ressaltando os detalhes e as circunstâncias específicas que ajudam a compreender esse todo" (Alves \& Fantinato, 2017, p. 20). Dessa forma, buscamos um detalhamento do curso PROEJA/MSI desde sua implantação, como do seu desenvolvimento, até o segundo semestre de 2016.

Após uma fase exploratória, cujo objetivo foi a delimitação mais precisa do objeto de estudo, procedemos à fase do trabalho de campo. Nesta fase, optamos pela forma de participante como observador, que é uma das formas da técnica de observação participante (Lüdke \& André, 2013). Nossa opção, por esta forma, se deu pelo fato de que o grupo de professores e gestores estavam cientes de que a investigação tinha como objeto o trabalho docente no PROEJA/MSI, mas não conheciam em que amplitude esse objeto seria focalizado. Assim, buscamos evitar mudanças no comportamento dos sujeitos observados (Junker, 1971 apud Lüdke \& André, 2013). Foi possível construir um diário de campo no qual foram registradas reuniões, conselhos de classe, conversas informais com gestores e ex-professores do curso e realizar as entrevistas 
com os professores. As entrevistas foram a estratégia dominante, porque o objetivo era a coleta de dados descritivos na linguagem dos professores, de modo a ter uma ideia sobre a forma como interpretavam o PROEJA/MSI e o próprio trabalho docente (Bogdan \& Biklen, 1994).

Com o objetivo de conhecer as trajetórias de vida dos professores, seus percursos profissionais e experiências de vida ao ouvi-los, as entrevistas seguiram uma abordagem biográfica, possibilitando "recolocar a questão da subjetividade ou do ator no centro das pesquisas sobre ensino e sobre a escola" (Tardif, 2001, p. 114). Além disso, as entrevistas foram realizadas com inspiração no método da entrevista compreensiva, que é um método muito próximo de outros: ao mesmo tempo em que se inspira na técnica da entrevista semidiretiva, invertendo, porém, instruções tais como a neutralidade e a amplitude da amostra, também se inspira em técnicas etnológicas de trabalho com informantes, sendo esses sujeitos privilegiados, cujos "dados qualitativos estão concentrados na palavra recolhida no gravador” (Kaufmann, 2013, p. 27).

Para fugir da hierarquia criada na interação entrevistador-entrevistado, apresentamos aos onze entrevistados cinco temas que abrangiam nosso objetivo. O primeiro tema foi "a socialização antes da formação profissional", e daí em diante eles decidiram a sequência de sua preferência para abordar os assuntos "graduação e pós-graduação", "experiência", "trabalho docente" e "PROEJA".

Dentro do limite deste artigo, vamos mencionar, de forma breve, os resultados das onze entrevistas, dando destaque para cinco relatos de maior significância para a temática da formação inicial e continuada de professores para a Educação de Jovens e Adultos na qual este trabalho está inserido. Todos os nomes a seguir são fictícios.

\section{Resultados}

Dos onze professores, nove nos disseram que tiveram a oportunidade de ensinar antes ou durante a formação inicial. Dentre esses, Irineu, Leandro, Sinésia e Eugênio ensinaram em nível superior; Tibério e Jaiane ensinaram em espaços informais, como a própria casa, e Hórus, Aspásia e Amon em cursos livres ou em treinamentos para outros profissionais.

A ideia de profissionalização que construímos, e na qual apoiamos o estudo, foi identificada nas entrevistas. Aspásia e Hórus compartilharam suas reflexões sobre a importância da formação pedagógica para a tarefa de ensinar. Irineu e Eugênio reconhecem que sua atuação se dá num complexo universo de poderes e relações sociais. Juno, André, Amon, Sinésia compreendem o seu papel social de ensinar algo a outrem. Assim, uma conclusão importante é a de que os professores entendem a docência como profissão, ainda que por ideias diversas e por formas subjetivas de representá-la. 
Das condições objetivas elencadas por Basso (1998), as que se destacam nas reflexões realizadas pelos professores são as que se referem à organização da escola em termos de planejamento e gestão - que dificultaram a institucionalização do curso e o atendimento às suas especificidades - e às possibilidades de troca de experiência e estudo coletivo, que não se consolidam pela perda da garantia de que todos os professores pudessem participar das reuniões da equipe do curso PROEJA/MSI. Na realização das entrevistas, percebemos como cada professor refletiu sobre as relações com a escola, com os conteúdos, com os alunos e com o que envolve os alunos.

Os professores Irineu e Leandro tinham planejado lecionar em nível superior, talvez porque, para eles, a motivação para o trabalho docente esteja relacionada ao prestígio social da ação pedagógica exercida no nível superior de ensino. Já a professora Sinésia expressa sua motivação pela crença de que seu trabalho pode fazer a diferença na formação dos estudantes.

Em relação à temática da formação inicial de professores, cinco relatos nos chamaram atenção. Passamos a registrá-los.

O professor Irineu, licenciado em Matemática, avaliou seu trabalho docente no PROEJA/MSI e levantou a hipótese de ter assustado os estudantes, criticando-se: "eu que não consegui aproveitar, digamos assim, o momento em que eu fui professor do curso". Ele, que trabalhou em todos níveis de ensino - técnico, PROEJA e graduação - dentro do campus Rio de Janeiro, devido à sua experiência exclusivamente com nível superior, antes de ingressar no IFRJ, avaliou que foi no PROEJA que sentiu mais diferença, pois não percebeu a modalidade e assim pensou que poderia usar a mesma didática que usava nos outros cursos técnicos integrados.

Além de auto avaliar seu trabalho, o professor Irineu quis registrar a questão objetiva da falta de espaço no campus Rio de Janeiro. Disse-nos ele: "eu já conversei [...] com a direção a respeito de eu montar uma sala para a Matemática, digamos assim. Mas, não vi interesse. Porque não tem sala [aqui, no sentido de que falta espaço]".

O professor Hórus, tecnólogo em Informação e pedagogo, nos disse que não tinha conhecimento nenhum acerca do ensino profissional na modalidade EJA. Mesmo com sua experiência em ensinar pessoas de diferentes idades, em cursos livres, ele entendeu que ali no PROEJA/MSI os estudantes precisam de mais atenção e há mais tempo para trabalhar o ser humano. Hórus nos disse: "a gente precisa estar mais atento, então, eu não sei se sem a Pedagogia eu conseguiria me adaptar tão simples ou fácil a esse modelo do EJA". Vargas e Fantinato (2011) alertam sobre a importância da preparação teórico-metodológica prévia para compreensão das especificidades de EJA.

Hórus fez, segundo ele, um desabafo durante a entrevista quando disse que, de forma geral, os professores não querem dar aula no curso PROEJA/MSI. Muitos o fazem porque precisam completar sua carga horária de trabalho, e o que se vê é que: 
tem professor que está no MSI que não tem, é, comprometimento algum com esse tipo pedagógico de ser e isso acaba prejudicando porque toda aquela sintonia que deveria existir a cada semestre alguns professores entram e acabam com essa sintonia (Prof. Hórus).

Hórus também falou da necessidade de repensar as condições objetivas, como carga horária, para que houvesse professores dedicados ao curso e os diálogos se tornassem frequentes. As professoras Sinésia e Juno destacaram a importância de professores que se dedicassem a pensar a modalidade EJA, como acontecia no início do curso.

O professor André, graduado em Farmácia, afirmou: "costumo usar uma frase que... Pedagogia não vai te ajudar a ensinar o que você não sabe". Concordamos com André na medida em que, na base da relação entre ensino e aprendizagem, o conhecimento e domínio do conteúdo é parte importante. Porém, percebemos que ele se distancia da ideia de conhecimento pedagógico-disciplinar (Sztajn, 2002), que se relaciona à elaboração e apresentação do conteúdo de maneira que seja compreensível aos estudantes.

De encontro à compreensão de André, a professora Aspásia, tecnóloga em Processamento de Dados, mesmo com todo o conhecimento adquirido em diversos contextos de sua área, disse-nos que se ressente da ausência do conhecimento pedagógico-disciplinar que a formação pedagógica poderia Ihe proporcionar.

O dito pelo professor Eugênio, licenciado em Física, sobre formação pedagógica foi o que mais se aproximou da EJA. Ao final da licenciatura, ele participava de um movimento de divulgação da ciência para o povo em geral que fazia parte de um plano ${ }^{1}$, com financiamento externo, implantado em 1985. E era nesse movimento que ele queria estar, pois ele já tinha a visão de que sua prática de ensino não se daria dentro do formalismo de sua disciplina. Ele desejava "fazer educação popular2" (Prof. Eugênio). Segundo esse professor, em sua licenciatura, ele estudou textos de Paulo Freire, Saviani, Gadotti. Dentre os onze professores, Eugênio foi o único que se referiu a esses autores, que são, no Brasil, referências para a educação popular e para a pedagogia histórico-crítica, que segundo Saviani (2013) é "o empenho em compreender a questão educacional com base no desenvolvimento histórico objetivo” (p. 76).

Ele também desejou que ficasse registrada sua reflexão sobre a diferença, que ele entende existir, entre um professor de Física e um físico. Segundo ele:

[...] Um professor de Física não é um físico [...] não é, são duas profissões muito diferentes, que a única coisa é esse nome aí, 'Física', que é igual, um é um físico, então, o jeito de pensar, o jeito de trabalhar, o trabalho dele experimental tem todo um tipo de coisa para ser feita, não é só a questão de ver a natureza, 
é a precisão, o método ... Um professor de Física é o cara que, na hora que cai um asteroide, o aluno vem perguntar o que aconteceu e eu não vou poder dizer 'Desculpe, eu sou físico, eu não sou astrônomo',[...] quando venta e cai um prédio lá, 'Desculpe, eu sou físico, eu não sou engenheiro de estruturas', né, então, você como físico pode dizer 'Ah, essa parte eu não entendo, essa parte eu não vou me meter, essa parte eu não vou falar' [...] (Prof. Eugênio).

Segundo Eugênio, a formação inicial não precisa ser multidisciplinar, o professor não tem que saber de tudo, mas o seu olhar tem que ser amplo, e para isso sua formação precisa ser mais ampla.

A riqueza do material empírico nos permite afirmar que concretizamos nosso compromisso não só de ouvir, mas de dialogar, trocar ideias, dando destaque sempre para os entrevistados, pois eles eram os atores principais.

\section{Reflexões Finais}

Na realização das entrevistas, percebemos como cada professor refletiu sobre as relações com a escola, com os conteúdos, com os estudantes e com o que envolve os estudantes. O pensar politicamente, que não é algo que se adquira fora da prática (Fernandes, 1987), leva o professor a perceber o quanto seu trabalho é permeado pelas condições objetivas, ao mesmo tempo em que, assumindo sua condição de agente social, pode atuar na direção da transformação e não da mera reprodução.

Ao refletir sobre o que faria diferente, caso voltasse a ensinar no curso, o professor Irineu nos disse que tentaria diminuir a cobrança e procuraria aumentar o interesse dos estudantes pela Matemática. Mesmo que isso Ihe custasse reduzir parte do conteúdo. Ele tentaria fazer com que os estudantes percebessem a importância daquele estudo.

Entendemos que a expressão "trazer o interesse" está associada à motivação. Quando the perguntamos se tentaria trabalhar com os conhecimentos trazidos pelos estudantes, Irineu respondeu que teria que aprender a fazer isso. De Vargas (2009) se refere a esse aprendizado dizendo que os professores de EJA de todas as disciplinas "são constantemente submetidos ao desafio de compreender o que, como, por quais estratégias seus alunos construíram seus saberes nas práticas sociais do trabalho" (p. 193, grifo da autora).

A investigação nos mostrou que os professores assumem a tarefa de ensinar no PROEJA/MSI sem debates sobre as concepções do Ensino Médio integrado à formação profissional e sobre a modalidade educação de jovens e adultos. Mostrou-nos também que a designação de professores para trabalhar no PROEJA/MSI, sem consultar-lhes sobre sua motivação para realizar esse trabalho ou sobre o conhecimento da modalidade, demonstra a ausência de preocupação com as especificidades do 
curso. Os relatos ratificaram os resultados de outros estudos, que, nos últimos anos, verificaram que a formação inicial para a EJA e EP ainda é incipiente, e como a experiência anterior nas modalidades não é habitual.

Pelas falas dos professores, reforçamos a importância de discussões que tomem a EJA como um campo de articulação teórico-prático. Foi possível identificar que, para alguns professores, a licenciatura não desenvolveu neles "conhecimentos e habilidades, atitudes e valores" que Ihes possibilitassem "permanentemente irem construindo seus saberes-fazeres docentes a partir das necessidades e desafios que o ensino como prática social Ihes coloca no cotidiano" (Pimenta, 1999, p. 18). Entendemos que o trabalho coletivo através do diálogo constante pode proporcionar o desenvolvimento de um arcabouço teórico que fundamente as discussões para o ensino na EJA e na EP.

Também percebemos nas falas dos professores o quanto eles trabalham isolados, dentro de suas salas de aula, e desconhecem o que acontece fora delas. Dessa forma, parece que as concepções dos professores sobre trabalho docente são marcadas pelo individualismo, pela falta de colegialidade (Tardif \& Lessard, 2014), e que tomam a experiência como afirmação de sua competência. Nesse sentido, o conviver (falar e ouvir) das diferentes linguagens e dos diversos campos específicos pode contribuir para a superação desse quadro (Pimenta, 1999).

Em outras redes de ensino, como a municipal e a estadual, os professores estão sendo cada vez mais alienados do seu trabalho, uma vez que se torna mais difícil que eles identifiquem suas escolhas nas ações que devem realizar com a finalidade da assimilação pelos estudantes do conhecimento historicamente elaborado e sistematizado. Nosso estudo evidenciou que tal fato ainda não ocorre com o trabalho docente do PROEJA/MSI. Acrescente-se que não foi percebido que o trabalho do professor no IFRJ esteja submetido a controle cada vez maior, ocasionando, na mesma intensidade, perda de autonomia do docente, que o leva a não se reconhecer no trabalho que realiza. Nesse sentido, vislumbramos condição favorável para o aprofundamento do diálogo, entre saberes das diversas áreas de conhecimento, que possa contribuir para a formação inicial e continuada dos professores.

Pela análise do material empírico, foi possível identificar o sentido e o significado que conferem ao trabalho docente, bem como as escolhas que fazem sobre o que e de que maneira ensinar, além de registrar seus conflitos e dúvidas. Consideramos que todos esses elementos do trabalho docente podem e devem ser compartilhados e norteadores de estudo coletivo. Ao compartilhar o trabalho docente individualizado, o estudo coletivo se torna caminho para as reflexões sobre o ensino. Assim, é possível superar a ideia de um ofício sem saberes e, pelas contribuições teórico-práticas, constituir um conjunto de saberes e fazeres que caracterizem a profissão docente. 


\section{Notas}

1 governo da época constatava que existiam áreas com importantes lacunas, que não podiam ser preenchidas satisfatoriamente pelos mecanismos e recursos disponíveis. Isso levou à opção de montar um programa de apoio específico. Tal iniciativa teve como contrapartida o interesse do Banco Mundial em apoiar um programa setorial de C\&T, em decorrência de sua mudança de estratégia, de urna política de ajuste estrutural para financiamento de projetos de alcance restrito (Reis Barrella, 1998). Retirado de: <http://repositorio.unicamp.br/bitstream/REPOSIP/286694/1/ ReisBarrella_Alzerina_M.pdf>.Acesso em: 27 mai. 2108.

2 Segundo Gadotti (2011), "um dos princípios originários da educação popular tem sido a criação de uma nova epistemologia baseada no profundo respeito pelo senso comum que trazem os setores populares em sua prática cotidiana, problematizando esse senso comum, tratando de descobrir a teoria presente na prática popular, teoria ainda não conhecida pelo povo, problematizando-a, incorporando-Ihe um raciocínio mais rigoroso, científico e unitário" (p. 36-37).

\section{Referências}

Alves, T. \& Fantinato, M. C. (2017). A Integração da Educação Profissional Técnica de Nível Médio à Educação de Jovens e Adultos: o trabalho docente no PROEJA. BOLETIM GEPEM, 70, 1425. [Disponível em http://doi.editoracubo.com.br/10.4322/gepem.2017.018., consultado em 10/06/2017].

Alves, T. (2018). Saberes e Fazeres dos Professores: A Educação Profissional Técnica de Nível Médio, na modalidade Educação de Jovens e Adultos. Tese de doutoramento. Niterói: Universidade Federal Fluminense.

Basso, I. S. (1998). Significado e sentido do trabalho docente. Cadernos CEDES, 19(44), 19-32. https:// dx.doi.org/10.1590/S0101-32621998000100003.

Bogdan, R. C. \& Biklen, S. K. (1994). Investigação Qualitativa em Educação. Porto: Porto Editora.

De Vargas, S. (2009). Estratégias não escolares de ensino-aprendizagem e formação de professores de EJA. In: M. C. C. B. Fantinato (Org.). Etnomatemática: novos desafios teóricos e pedagógicos (vol. 1), (pp. 193-201). Niterói: EDUFF.

Fernandes, F. (1987). A formação política e o trabalho do professor. In D. B. Catani; H. T. Miranda; L. C. Menezes \& R. Fischmann (Orgs.). Universidade, escola e formação de professores (pp. 13-37). São Paulo: Ed. Brasiliense.

Gadotti, M. (2011). Educação de jovens e adultos: correntes e tendências. In M. Gadotti \& J. E. Romão (Org.) Educação de Jovens e Adultos: teoria, prática e proposta. (12 ed). (pp. 35-47). São Paulo: Cortez.

Kaufmann, J. C. (2013). A Entrevista Compreensiva: um guia para pesquisa de campo. Petropólis, RJ: Vozes; Maceió, AL: Edufal.

Lessard, C. \& Tardif, M. (2008). As Transformações atuais do ensino: três cenários possíveis na evolução da profissão de professor? In M. Tardif \& C. Lessard (Orgs.). O ofício de professor: história, perspectivas e desafios internacionais (pp. 255-277). Petrópolis, RJ: Vozes.

Machado, M. M. (2009). A educação de jovens e adultos no Brasil pós-Lei n. ${ }^{\circ}$ 9.394/96: a possibilidade de constituir-se como política pública. In M. M. Machado (Org.), Em Aberto, 22(82), 17-39. 
Moura, D. H. \& Henrique, A. L. S. (2012). PROEJA: entre desafios e possibilidades. Holos, 2, 114-129.

Nicodemos, A. (2013). O Ensino de História na Educação de Jovens e Adultos - Perspectivas e Contradições do Trabalho Docente na Re (Criação) Crítica do Currículo em Sala de Aula. Tese de doutoramento. Niterói: Universidade Federal Fluminense.

Nóvoa, A. (1998). Relação Escola-Sociedade: "Novas respostas para um velho problema". In R. V. Serbino et al. (Org.). Formação de Professores (pp. 19-39). São Paulo: Fundação Editora UNESP.

Oliveira, D. A. (2004). A reestruturação do trabalho docente: precarização e flexibilização. Educação \& Sociedade, 25(89), 1127-1144.

Pimenta, S. G. (1999). Formação de Professores: identidade e saberes da docência. In S. G. Pimenta (Org.). Saberes Pedagógicos e atividade docente (pp. 15-34). São Paulo: Cortez Editora.

Santos, J. A. (2015). A Trajetória da Educação Profissional. In E. M. T. Lopes; L. M. de F. Filho \& C. G. Veiga (Org.). 500 anos de educação no Brasil (pp. 205-224). Belo Horizonte: Autêntica.

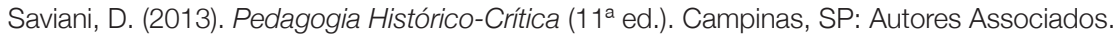

Sousa Neto, M. F. de. (2005). O Ofício, a Oficina e a Profissão: reflexões sobre o lugar social do professor. Cadernos Cedes, 25(66), 249-259. [Disponível em http://www.cedes.unicamp.br., consultado em 29/08/2017].

Sztajn, P. (2002). O que precisa saber um professor de Matemática? Uma revisão de literatura americana dos anos 90. Educação Matemática em Revista, Ano 9, n. 11A - Edição Especial: Formação de Professores. São Paulo: SBEM, 17-28.

Tardif, M. (2001). Os professores enquanto sujeitos do conhecimento: subjetividade, prática e saberes no magistério. In V. M. Candau (Org.). Didática, currículo e saberes escolares ( $2^{\mathrm{a}}$ ed) (pp. 112-147). Rio de Janeiro: DP\&A.

Tardif, M. (2012). Saberes Docentes e Formação Profissional (14ª ed.). Petrópolis, RJ: Vozes.

Tardif, M. \& Lessard, C. (2014). O trabalho docente. Elementos para uma teoria da docência como profissão de interações humanas (9a ed.). Petrópolis, RJ: Vozes.

Vargas, S. \& Fantinato, M. C. C. B. (2011). Formação de Professores da Educação de Jovens e Adultos: diversidade, diálogo, autonomia. Revista Diálogo Educacional, 11(34), 915-931. 


\section{Telma Alves}

Instituto Federal de Educação, Ciência e Tecnologia do Rio de Janeiro - IFRJ; Email: tel.alv@gmail.com ORCID 000-002-7867-0907

Maria Cecilia Fantinato Universidade Federal Fluminense - UFF; Email: mcfantinato@gmail.com ORCID 0000-0001-8344-2071

\section{Correspondência}

Rua Jornalista Irineu Marinho número 522/ apartamento 202 - CEP 24230 126 - Niterói - Rio de Janeiro - RJ - Brasil

Data de submissão. Outubro de 2018

Data de avaliação: Janeiro de 2019

Data de publicação: Setembro de 2019 